\title{
From Method to Post Method: A Panacea!
}

\author{
Nima Shakouri Masouleh \\ Roudbar Branch, Islamic Azad University, Iran \\ Tel: 91-1184-6337 E-mail: Shakouri54@Gmail.com
}

Received: January 13, 2012

Accepted: February 11, 2012

Published: April 1, 2012

doi:10.5539/elt.v5n4p65

URL: http://dx.doi.org/10.5539/elt.v5n4p65

\begin{abstract}
The foundation of language teaching has undergone many changes. The rise and fall of language teaching methods depends upon a variety of factors extrinsic to a method itself and often reflects the influence of profit-seekers and promoters, as well as the forces of the intellectual marketplace. There was always a source of contention among people that what the secret of a method life is. In this paper, the writer investigated why once have various teaching methods come into vogue and then disappeared? Some contradicted the method, while others came to provide a complementary view. The writer with a critical lens questioned the concept of post-method which qualitatively, as Akbari (2008) held, is not that much different from the term method. Furthermore, the author claimed the concept of post-method is not plausible by novice teachers. For the fulfillment of post-method perspectives, the whole system must be touched upon, not just a teacher as the key feature of post method. And if it is said there should be an attempt to find an alternative to method, is it really logical to imagine that even a novice teacher must seek for it? The one who first must be provided with some packages of principles in order to begin his teaching job? There is not a place to discuss whether a teacher should adopt a method or not, but what is plausible is that method is always present everywhere even in the body of the phrase like post-method. The writer, in the paper, attempted to shed lights into the concept of methods, beyond methods, post-method and, in a nutshell, what is going on in the history of language teaching.
\end{abstract}

Keywords: Method, Reflective teaching, Effective teaching, Post method

\section{Introduction}

The profession of language teaching has undergone many changes. Historical accounts of the profession tend, therefore, to describe a succession of method, each of which is more or less discarded in due course as a new method takes its place. Whether the teacher decides on the fate of a method or other factors is a matter of secrecy. But what is clear is that there is a consensus among scholars that the ultimate goal of various methods is to facilitate the process of learning. But what lamented our century-old obsession (Brown, 2002) is that why methods are unproductive and misguided and why we are vainly in search for new methods that would serve as a final answer. That search might have begun around 1880 with Francois Gouin's publication of The Art of Teaching and Learning Foreign Languages in which his series method was advocated. It seems the commonest solution for the teacher to cope with the demands of students in class lies in the adoption of a new teaching approach or method. From the survey of approaches and methods presented, the direct method was enthusiastically embraced in the early of the $20^{\text {th }}$ century as an improvement over grammar translation method. In the $1950 \mathrm{~s}$, the audio-lingual method was thought to provide a way forward. By the late 1960s, audio-lingual lost its popularity due to its theoretical and practical shortcomings particularly regarding the use of memorization and pattern drills. However, students complained about the frustrating and boring classes and found themselves incapable of transferring their knowledge. Reraising the necessity of an awareness of foreign language rules, experts found themselves in a quest for a modified up-to-date version of grammar translation method which came to be dubbed by some as the codgnitive-code learning. Its advocates put forth two major issues: (1) conscious knowledge of the rules must be preceded the use of them; and (2) the learners have to be given opportunities to use the language creatively. Despite the inclination of practitioners to employ cognitive-code learning theory in their classes, it failed to be practiced as a method due to the lack of methodological guidelines. Nevertheless, together with humanistic psychology it did succeed to lay the foundation of Designer Methods (i.e., silent way, suggestopedia, community language learning, total physical response). They all emphasize the necessity of understanding and learning language in a stress-free environment.

Above all the advocated methods and approaches, the most groundbreaking method lasting so far appears to be community language teaching followed by task-based instruction. This results in a new current in the field of 
language teaching. Prabhu (1990) contended that there is no best method, to him the philosophy of no method can be employed in a class. Henceforth, the majority of scholars were after an alternative to method instead of an alternative method (Kumaravadivelu, 2006). Meanwhile, practitioners came to this trend that teaching should be democratic. Education is more than training. It is a process-oriented, synergic, and adhockery phenomenon. Knowledge does not belong to one person whose role is limited to a mere distributor (sender). Knowledge belongs to two: students and teacher. What is visible in the field of language teaching is a shift in the role of teacher from a disseminator to a learning facilitator, and students from a passive receiver to a critical thinker. In such an atmosphere, the learners will make an attempt to develop critical thinking: to develop their own view of the world.

From now on, the inclination of methodologists towards approach becomes evident. An approach of language pedagogy is not just a set of static principles set in a fixed framework. It is dynamic. And a significant feature of this dynamicity is change. Change involve innovation, and innovation involves being free to employ one's plausibility in maximizing the process of learning. As Brown (2002) claims, "The interaction between one's approach and classroom practice is a key to dynamic teaching" (p. 11).

\section{From Middle Age to $18^{\text {th }}$ Century: Language Is Made by Accident}

The profession of language teaching has undergone many changes. Before the foundation of the Roman empire, the Romans studied Greek as a second language. 'Latin' and 'Greek' were learnt almost simultaneously. The Romans engaged Greek tutors, nurses, Greek-speaking slaves and servants in their household. The process of second language acquisition was similar to the acquisition of the first language, that is, by direct contact with the speakers of the foreign language, by imitation and reproduction of the sounds, words and sentences of the target language. During the Middle Ages, as the Roman empire expanded, Latin became the international language of the western world, the language of church and state. It was believed Latin provides a mental gymnastic for the brain. Latin was then taught as any living language was taught - at first orally, through an imitation of the language of the native speaker, and later through extensive as well as intensive reading and writing. Two prominent figures of $17^{\text {th }}$ century, are John Locke and Basedow (Simon, 1998) who followed the ideas of Comenius who devised new methods of teaching based on the principles of imitation, repetition, and practice in both reading and speaking form. Comenius stressed the importance of sensory perception and intuitive learning. In his own text books, Comenius introduced pictures and illustrations so that the child's sensory perception would lead him to think first and then to express. In this manner, grammar was acquired indirectly by induction. John Locke and Basedow also like Comenius favoured the removal of grammar from any language learning program. They advocated the natural method of learning a language which meant, by and large conversation practice in the target language and comparison of the first and second languages. Locke held that languages were not made by rules of art, but by accident. By the end of the eighteenth century, the teaching of Latin grammar had become an end in itself and had begun to influence even the teaching of modern languages which, as a result, came to be taught with the same methods as Latin and justified by the same arguments of mental discipline

\section{The $18^{\text {th }}$ century: Lack of Theoretical Basis in Second Language Teaching}

Early attempts at language teaching almost entirely lacked a theoretical base. Two opposing currents may be seen in language learning between the Renaissance and 1800. The first trend was along in lines with common sense, not yet infected by the virus of formal 'grammaticalism'. In fact, languages were taught by living contact with them, whether in their oral or their written form (Byram, 2000). As Howatt (1984) asserts, "Early language teaching material relied mainly on texts, and the dialogue form as a slice of linguistic life" (p. 5). The text was accompanied by mechanical translation consisting of a set of a series questions and arguments related to the topics and activities of everyday real life such as farming, hunting and so on (Howatt, 1984; Byram, 2000). The techniques employed was catechistic (Howatt, 1984), whereby questions are used as prompts to the memory and serve to break the text into digestible chunks which can be learnt by heart (p. 5). The second trend which began after the Renaissance was based on a systematic teaching of grammar based on paradigms, tables, declensions and conjugations. In a nutshell, memorization of rules, long lists of words and their synonyms and antonyms provide a mental gymnastic for the brain (Byram, 2000). This traditional belief may be explained by turning to the textbooks used for so many decades by teachers. According to Byrom (2000), "turning to the textbooks perpetuates an opinion that appears contrary to common sense and science" (268). The important feature of textbooks, in this period, is an attempt by their compilers to codify the language into frozen rules of syntax and morphology two sections to be explained and to be memorized. Working on oral language was kept to absolute minimum. The books were usually divided into two parts: one giving the rules and other giving some mechanical translation form L2 to L1. The immediate objective of this was to employ the rules learned. Because of shaky theoretical value in Latin, gradually, the popularity of Latin decreases. As, Byrom (2000) holds, modern educational psychology has discovered that a double fallacy lies in the traditional belief about the formative value of Latin and of the grammatical method as a means of mental training. 
Latin has no unique value for mental discipline (p. 264).

\section{4. $19^{\text {th }}$ Century: The Reform Movement}

At the start of nineteenth century, it was Ollendorff's language courses which combined brief presentations of grammar points with massive translation practice that came into popular use around. In the mid-nineteenth century, Karl Plotz, a German educationist, adapting Seidenstucker's principles popularised the grammar translation method as the principal method of teaching modern languages in schools. Plotz's method was divided into two parts: (1) rules and paradigms, and (2) sentences for translation into and out of the second language. In the later half of the nineteenth century, there arose a number of reactions against the grammar-translation method which finally developed into the Direct method. In the end, grammar-translation was attacked as a cold and life-less approach to language teaching, and it was blamed for the failure of foreign language teaching (Stern, 1983). The reform movement which is the end product of nineteenth century is generally considered as the last thorough and extensive reorientation of language teaching. This movement in the last two decades of the nineteenth century was preceded by the work of a few individual reformers among them we can name:

$>$ Jean Joseph Jacotot (1770-1840) was the first to employ and recommend monolingual methods for the language classroom.

In 1853 Claude Marcel (1793-1876) made a proposal to make the teaching of reading the first priority in foreign language teaching through his Language as a Means of Mental Culture and Inrernational Communication.

$>$ In 1866 Heness started a private school for teaching languages by a 'natural method' as an extreme reaction against the grammar-translation methods of Plotz,

$>$ Ahn and Ollendorf, in 1874, advocated the abolition of translation and grammar rules and emphasised the development of the four language skills.

In 1880, Francois Gouin (1831-96) published his The Art of Teaching and Studying Languages and held the view that the structure of a language text reflected the structure of the experience it described. He assumed that sequentiality was the primary feature of experience and that language could be best learnt in terms of sequential structures. Historically the development of the direct method is thus closely linked with such practical teaching reformers like Gouin and Vietor on the one hand, and with the development in linguistic theory, philology, and phonetics, on the other.

\section{20 ${ }^{\text {th }}$ Century: A Shift from Method to Post-method}

In the $20^{\text {th }}$ century, two sets of language teaching methods emerged; the first set borrowed theories from psychology, linguistics, and sociolinguistics whereas the second set was based on individual philosophies of method developers such as Asher's total physical response, Curren's community language learning, Lozano's suggestopedia and Gattegno's silent way. Nevertheless, Kumaravadivelu (2006) prefers to call them 'designer nonmethods' since none of them, in his view, deserve the status of a method. To him, for a method to be considered a method must satisfy at least two criteria: First, it should be informed by a set of theoretical principles derived from feeder disciplines and a set of class procedures directed at practicing teachers. Accordingly, both principles and procedures should address the factors and processes governing learning and teaching; second, a method should be able to guide and sustain various aspects of language learning and teaching operations in terms of curricular contents, language skills, and proficiency level.

Late in the twentieth, we have some attempts on the part of some pedagogists to evaluate the concept of methods in a way that the legitimacy of the concept of method came under questions. In 1994, an attempt at finding an alternative to methods instead of an alternative method culminated in the introduction of the post method era (Salmani-Nodoushan, 2006).

As Salmani-Nodoushan (2006) maintains the first steps towards making language teaching scientific were taken in the twentieth century. In the $20^{\text {th }}$ century, as he states two sets of methods emerged; the first set borrowed theories from psychology, linguistics, and sociolinguistics, whereas the second was based on individual philosophies of method developers. Salmani-Nodoushan (2006) in his paper 'Language Teaching: State of the Art' traces three eras in the history of language teaching in the $20^{\text {th }}$ century: the method era, the beyond method era and the post method era. It is worth a moment to elucidate the features of each era.

\subsection{Method Era}

Although the question of how to teach languages has been debated for centuries, the conceptualization of language teaching in terms of teaching methods has been the heated debate of the last century. While some scholars considered the method as the cause of failure and success in language teaching, for others little importance was 
assigned to methods and methods are considered merely as instruments in the hands of teachers (Simon, 1998) to provide opportunities for learners to acquire language (Salmani-Noudoushan, 2006). Mackey (1950) also asserts, after centuries of language teaching, there is no systematic reference to the meaning of method. Much of the field of language method has become a matter of opinion rather than of fact (Salmani- Nodouhsan, 2006).

Methods define language differently (Salmani-Nodoushan, 2006). Mirhasssani (2003) states that the meaning of method depends on the method. Method means different things to different people. For some, it means a set of procedures; for others, the avoidance of some teaching procedures. For some, it is the primacy of a language skill; for others, it is the type and the amount of vocabulary and structure. Different meanings of method can be inferred form the regulations on language teaching method issued by departments, boards, ministries of education. For example, in the decade of 20 and 30, there was a consensus among methodologists that teachers to move towards the control of vocabulary. Mackey (1950) believes that all teaching, whether good or bad, must include some sort of selection, some sort of gradation, some sort of presentation, and some sort of repetition. Selection, because it is impossible to teach the whole of a field of knowledge; we are forced to select the part of it we wish to teach. Gradation, because it is impossible to teach the whole of what we have selected at once; we are forced to put something before or after something else. Presentation, because it is impossible to teach without communicating or trying to communicate something to somebody. Repetition, because it is impossible to learn a skill from a single instance; all skill depends on practice. In fact, all language-teaching methods, by their nature, are necessarily made up of a certain selection, gradation, presentation and repetition of the materials. It is therefore through these four inherent characteristics that one may discover how one method differs from another.

In the second half of the twentieth century, we have experienced different definitions of methods. For Anthony (1963), method is the middle rung in the ladder between approach and technique. That is to say, approach relates to a set of correlative assumptions about language and language teaching and learning, method is a level at which theory is put into practice i.e., an overall plan for the orderly presentation of materials and technique refers to a trick, stratagem, or contrivance used to accomplish an immediate objective. In short, it is what happens in the classroom. This tripartite framework is hierarchical in the sense that approach informs method and method informs techniques. Larsen-Freeman (1986) subsumes method under principles and techniques. The principles refer to the theoretical framework of the method: a set of insights derived from theoretical and applied linguistics, while the techniques refer to what occurs in the classroom; that is, the activities and procedures derived from the application of the principles. Richards and Rodgers (1982), write about methods as an umbrella term comprising approach, design and procedure. To them, a method is theoretically related to an approach, is organizationally determined by a design and is practically realized in procedure. In the early twenty century, according to Kumaravadivelu (2006), the term method subsumes principles and procedures. Classroom events, activities, techniques can be covered under procedure.

Richards (1990) maintains for the development of method there are two routes: One is through the syllabus and the other is through a theory of learning processes and instructional procedures. In the first half of the twenty first, there was a consensus among methodologists and teachers to move towards the control of vocabulary; in such a way, vocabulary is considered as a major component of syllabus. Ogden (1930) and West (1953) are among those who share in this view (cited in Salmani-Nodoushan, 2006, p. 173). Among those who are interested in grammar, Palmer (1921) was notable. To Palmer (1921), grammar is defined as a system underlying the patterns of speech. This paved the way for lying the foundations of grammatical syllabus. Such a syllabus affords a graded sequence of patterns and structures for courses and course materials (Salmani-Nodoushan, 2006). Later, this structural syllabus was associated with a situational approach to contextualizing and practicing syllabus items, thus resulting in what was later called the structural-situational approach (Richards, 1990). In the United States, of course later, a similar attempt was made by Charles Fries and his colleagues (1961, cited in Salmani-Nodoushan, 2006, p. 173) and led to the emergence of word lists and substitution tables which served as frames for pattern practice. Fries as a structural linguist applied structuralism to language teaching and syllabus deign. The perspective that the content of language can be explained in terms of vocabulary and grammar had a lasting influence on methods (Richard, 1990). Such views make the cornerstones of what Nunan (2001) termed as designer methods including Asher's Total Physical Response and Gattegno's Silent Way, Curren's community language learning and Lozanove's suggestopedia. It is also embodied in the audiolingual method. However, in 1959, it was attacked by Chomsky. Chomsky's key argument on structural linguistics is to show its inadequacy in explaining complex or ambiguous sentences. He demonstrated such analysis was insufficient for syntax, which is what Chomsky's original research was focusing on, arguing that since an endless number of sentences can be uttered, it makes the collection of all of them impossible.

It was not until very late in the $70 \mathrm{~s}$ and 80 s that the most serious challenges to the structural syllabuses emerged in the form of notional syllabuses on the one hand (Wilkins, 1976), and ESP movement on the other (Robinson, 1980). 
Both reject Lexico-structural syllabuses. Among the reasons that become the source of contention among many people was, once the basic vocabulary and grammar of the target language had been mastered, the learner would be able to communicate in situations where English was needed for general, unspecified purposes. Consequently, Wilkins redefines the language content of the structural syllabuses, and introduces notional-functional syllabus. He still goes strong that for communication to take place language content for general purpose must include not only grammar and vocabulary but also functions (i.e., the purposes for which the language is to be used), the notions people need to communicate about, the situations in which the language need to be used and the roles the learners might play. To put this syllabus into practice, the Council of Europe developed a now well-known version of notional syllabus - the threshold level (Van Ek \& Alexander, 1980), in which the content of language is no longer identified by vocabulary, grammar, notions and functions. Rather, the learners' communicative needs, though cost-effective, were determined. Looking at this through a critical lens, it is undeniable to say that Structural-situational, aural-oral, audio-lingual, notional-functional are content-oriented.

Another route to the development of some other methods is instructional theory. Methods based on an instructional theory are two-dimensional: (1) a psycholinguistic dimension, containing a theory of learning that describes learning strategies and processes and that specifies the conditions necessary for these processes to be effectively utilized by learners, and 2) a teaching dimension, containing an account of the teaching and learning procedures to be followed and of the role of teachers and learners in the instructional process (Richards, 1990). Thus, what Asher (1977), Curran (1976), and Gattegno (1976) have done is prompted not by reactions to linguistic and sociolinguistic theories but rather by their personal philosophies of how an individual's learning potential can be maximized (cited in Salmani-Nodoushan, 2006, p. 174). Unlike the syllabus-oriented methods of the past which began with an a priori specification of course objectives and syllabus content, in the more recent methods of language teaching, syllabus is an outcome of the instructional procedures - a posteriori syllabuses (Salmani-Noodushan, 2006)

The demise of method

For Kumaravadivelu (2006), method has a magical hold on us; the obsession becomes stronger even after the so called demise of methods. Brown (2002) makes frequent references to the death of methods - interred methods..., the requiem of methods. For post-methodologists, the concept of method becomes a bogeyman for the following reasons:

1) methods can't be realized in their purest form in the classroom according to the principles of their originators;

2) methods are very limited and never applied universally. Methods never claim universality;

3) types of activities, teaching techniques used are preplanned, better to say prescribed; and

4) the role of teacher is marginalized. The teacher submits herself or himself to the method. Through a process of marginalization and self marginalization, teachers' practical knowledge does not find the space and the scope to be regarded as visible, and consequently, fails to become part of the accepted knowledge of the discourse community (Akbari, 2008).

\subsection{Beyond Methods}

As Richards (1990) insists, "Methods have a life beyond the classroom" (p.13). Richards (1984) in his paper, "The Secret Life of Methods' also states "the rise and fall of methods depends upon a variety of factors extrinsic to a method itself and often reflects the influence of fads and fashions, of profit-seekers and promoters, as well as the forces of the intellectual marketplace" (p.13). The fate of a method to him depends on the form in which the method is available to the learners. Some methods are available to the learners in the form of materials. That is, a textbook reflects the principles of selection, organization and presentation that a method follows. For teachers who follow such methods as audiolingual and communicative there are no need to be instructed. The textbook talks and shows the way. In contrast, the teachers following the textbooks which are the production of instructional philosophies and which are dependent solely upon the teacher's skill requires special courses. In fact, methods, such as silent ways and suggetopedia that lead to texts have a much higher adoption and survival rate than those which do not. Among the other factors that play a role in the fate of a method include the credibility that the publishing company gives to methods. They need to be acknowledged as legitimate and valid responses to genuine educational issues. To better appreciate this kind of support, imagine that the minister of education of your country gave official approval to the direct method. It became the only approved method for teaching foreign languages. This will become a boom for publishers, thus, to increase their circulation. However, like the silent way and counseling-learning, it could not readily be translated into textbooks and materials, and this was one reason why it failed to survive despite the support it received in high places. Receiving support and gaining credibility are not deniable. Methods must, above all, address accountability (Richards, 1990). Accountability (or evaluation) as a missing element in the development 
of elements, has an established role in the process of curriculum development. Richards (1990) outlines the following additional procedures in the development of curriculum development:

1) situation Analysis, in which parameters of language development are determined;

2) needs Analysis, in which the language needs of the learners are assessed;

3) task Analysis, which determines the required linguistic task to be performed by learners together with the communicative and linguistic demands of the task;

4) goal Setting, which determines the required linguistic objectives based on the learner's entry level, communicative needs, and program constraints;

5) selection of learning experience, which determines the procedures for the attainment of objectives; and

6) evaluation, which could be both formative versus summative and product-oriented versus process-oriented.

Such a curriculum-based approach to language teaching is known as the Language Program Design (Salmani-Nodushan, 2006). The important issues, then, are not which method to adopt (select), but how to develop procedures and instructional activities which will enable program objectives to be attained. This is not a question of choosing a method but of developing methodology.

A claim that all methods make is that the adoption of a specific method will lead to higher levels of language achievement than the use of other methods. Long (1983, cited Salmani-Nodoushan, 2006) argues that the effectiveness of methods can be evidenced in either of the two ways: absolute effectiveness, and relative effectiveness. The former can be assessed with a survey of the internal structure of the method itself. The latter, however, calls for a comparative survey across different methods. No matter which type of method effectiveness is in focus, Salmani-Nodoushan (2006) counted a number of issues that must be addressed in any evaluation process:

$>$ the goals and objectives of the program need to be described, and criterion measures specified;

$>$ once an instructional theory takes the form of a method, with theoretical bases in language and learning theory and operationlized practices in syllabus design and teaching procedures, claims made at each level of method organization must be regarded as hypotheses awaiting verification or falsification;

the validity of the items contained in the syllabus must be guaranteed. A point of caution, however, is that most methods, to date, are based on shaky empirical pedestals. It should be underlined that if the methodology of language teaching is to move beyond the domain of speculation and dogma, its practitioners must become more seriously concerned with the issues of accountability and evaluation. This, in turn, means shifting our attention (from methods) towards the relevant facts and procedures of curriculum development.

Such a shift of attention has received a unique name - the beyond method era. The characteristics of the beyond method period are three-fold: (a) evaluation of the scope and nature of methods, (b) redistribution of theorizing power among practitioners and theorizers, and (c) learner autonomy and language learning strategies. Beyond method is based on the claim that the notion of good or bad method per se is misguided, and that the search for an inherently best method should be replaced by a search for the ways for the interaction of teachers' and specialists' pedagogic perceptions. All of these claims boil down to what is called teacher plausibility (Salmani-Nodousha, 2006).

As Samani-Nodoushan (2006) states the beyond method era was realized in two different forms: (a) effective teaching that suggests applied linguists should theorize and teachers should practice those theories. In fact, effective teaching is the result of the cooperation between theorizers and practitioners and (b) reflective teaching, in contrast, suggests theorizing should be put in the shoulder of teachers rather than applied linguists (Widdowson, 1990).

\subsection{Post-method Era}

The notion of methods came under criticism in the 1990s. Some spoke of the death of the methods and approaches, so the term post-method era was sometimes used. The early undocumented roots of post-method can be traced to what the profession has called eclecticism. The post-method condition questions the legitimacy of the concept of the method. Different from the conventional methods, the new pedagogy is said to be more flexible since it takes macro strategies to shape microstrategies. Frankly speaking, the argument of methodology rests on two well-known concepts: globalization and post modernism. The concept 'post-method' is a newly born infant of globalization and its ultimate product of postmodernism.

In an attempt to distinguish between post method and the forgoing heterodoxies, Kumaravadivelu (2006) suggests that the post method paradigm is an attempt at finding an alternative to method rather than an alternative method. Also, the need to look beyond the notion of method has emerged because of existing contradiction between method 
as conceptualized by theorists and method as actualized by practitioners. Again Kumaravadivelu (2006) informs us from the hostility that is deep rooted between theorizers and practiotioners. Salmani-Nodoushan (2006) takes an optimistic look at this and claims it seems reasonable to encourage both theorizers and practitioners to compromise in a more favorable ways. The post-method condition argues that language teachers are not to imprison themselves and their students in any method even an eclectic method. Unlike these plausible features, Ramin Akbari (2008) claims that the post-method is qualitatively not much different from method because both of them ignore or misrepresent the realities of the classroom and impose their own version of hypothetical reality. Akbari (2008) further adds:

While method has ignored the realities of teaching and language teachers, post-method has ignored the realities of teaching and language teachers. By making too many demands of teachers, the post-method pedagogy, in practice, turned a blind eye to the social, political and cultural realities of language teaching contexts and the limits within which teachers operate. (p. 642)

Kumaravadivelu (2006) further outlines the characteristics of the post-method condition in such a way as to signify: First, teacher autonomy can be justified by believing that teachers have potentials: teachers know not only what to teach but also how to act autonomously within the academic and administrative constraints imposed by intuition, curricula, and textbooks. To him, autonomy, from a narrow sense, seeks to develop in learners a capacity to learn to learn - academic autonomy, whereas from the broad view learners goes beyond that and includes a capacity to learn to liberate as well-liberating autonomy. Kumaravadavilu further adds if academic autonomy enables learners to be effective, liberatory autonomy empowers them to be critical thinkers. Meaningful liberatory autonomy, according to Kumaravadavilu, can be promoted in language classroom by:

$>$ encouraging the learners to assume the role of ethnographers to investigate and understand how language as ideology served vested interests;

asking them to reflect on their developing identities by writing diaries... related to the social world;

$>$ helping them in the formation of learning communities where they develop into unified, socially cohesive, mutually supportive groups seeking self-awareness and self improvements; and

providing opportunities for them to explore the unlimited possibilities offered by online services and bringing back to the class their own topics for discussions, and their own perspectives on those topics.

The second feature of post-method refers to the principled pragmatism that reveals itself in the form of teacher's sense of plausibility. Teachers' plausibility refers to subjective understanding of what the teacher can do. Teacher's plausibility connotes the involvement of both teachers and students in the learning activity (Salmani-Nodoushan, 2006). Principled pragmatism is based on Widdowson's (1990) notion of pragmatics of pedagogy which construes the immediate activity of teaching as the medium through which the relationship between theory and practice can be realized. Accordingly, Kumaradivadilu (2006) takes the principles of post-method era a point of departure to propose a strategic framework for L2 teaching. Of course, this framework, as he claims, is offered not as a dogma for uncritical acceptance but as an option for critical appraisal. Better to say, the framework is a suggestion (maybe a responsibility) on the part of teacher to foster their potentials of teaching. The framework is composed of 10 macrostrategies that can operationalized in the classroom through microstrategies.

1. Maximize learning opportunities.

2. Facilitate negotiated interaction.

3. Minimize perceptual mismatches.

4. Activate intuitive heuristics.

5. Foster language awareness.

6. Contextualize linguistic input.

7. Integrate language skills.

8. Promote learner autonomy.

9. Ensure social relevance.

10. Raise cultural consciousness.

Such strategies are considered theory-neutral since they are not confined to any theory of language learning and teaching. What is plausible here is a shift in the role of teachers form disseminators to strategic teachers and strategic researchers. The teacher is nor considered as a mere sender of information and the learner not as an empty 
vessel that must be filled. As Kumaravadivelu states a strategic teacher spends time reflecting on the process of learning and teaching; stretching their knowledge, skill and attitude to stay informed and involved.

Postmethod condition was later enriched by Kumaravadivelu's (2003) attempt to provide the fundamentals of the postmethod pedagogy as a three-dimensional system consisting of the pedagogic parameters of particularity, practicality, and possibility. By practicality, it means any language pedagogy must be sensitive to a particular group of teachers, teaching a particular group of learners, pursuing a particular set of goals within a particular institutional context embedded in particular sociocultural milieu. To phrase in another word, as Probhu (1990) states there should be a relationship between the teaching context and the applied methodology. Pedagogy of practicality aims for a teacher-generated theory of practice. This assertion is premised on a rather simple and straightforward proposition: No theory of practice can be useful and usable unless it is generated through practice (Kumaravadivelu, 2001). Thus, this must be a myth to consider teachers as consumer and theorists as the only conceiver of knowledge. For Prabhu (1990) such teachers who are apt to create theories have an unexplainable sense of what makes a good teaching which is called a sense of plausibility is. And, the parameter of possibility is derived mainly from Freirean critical pedagogy that seeks to empower classroom participants so that they can critically reflect on the social and historical conditions contributing to create the cultural forms and interested knowledge they encounter in their lives" (Mahmoodzade, M. 2011).

\section{Conclusion}

Teaching English as a foreign language has always been a controversial issue. Various teaching methods have come into vogue and disappeared. Ethically speaking, the traditional idea of method reduces experienced teachers to the state of mindless robots programmed to carry out the methodological suggestions. However, following a method or a blend of methods seems to be useful for novice teachers who have recently started their teaching since each method provides a pack of suggestions including a set of prescriptions on what teachers and learners should do in the classroom. And it seems unreasonable to expect a novice teacher uses his/her sense of plausibility different times of class. Prescriptions allow the teachers to decide what materials to teach, when and how should be taught and for learners what approach they should take toward learning (Salmani-Nodoushan, 2006). As Akbari (2008) asserts, "Missing form post-method is how teachers are prepared to perform their duties as post-method practitioners because the post-method view heavily emphasizes teacher qualifications" (p. 642). How ever, the adoption to a particular method on the part of even experienced teachers is not undeniable. Although learning faster and easier exists at the heart of every one of us, the assumption is that there are many teachers that require knowledge or skill to teach in the post-method fashion. For the post-method pedagogy to take hold, change should begin with the academic community which lays the foundations for teacher education and certification, norms of practice, standardization of language tests, as well as teacher hiring and firing policies. In other words, change should be multilateral because the requirements for a post-method pedagogy are too demanding to be fulfilled by teachers acting as rebels against their discourse (Akbari, 2008).

\section{References}

Akbari, R. (2008). Post-method discourse and practice. TESOL QUARTERLY, 42(4), 641-652.

Antony, E. M. (1963). Approach, method, technique. English Language Teaching, 17, 63-67. http://dx.doi.org/10.1093/elt/XVII.2.63

Brown, H. D. (2002). English language teaching in the post-method era: Towards better diagnosis, treatments, and assessment. In J. C. Richards \& W. A. Renandya, Methodology in language teaching: An anthology of current practice (pp. 9-18). Cambridge: Cambridge University Press.

Byram, M. (2000). Routledge encyclopedia of language teaching and learning. London: Taylor \& Francis Routledge.

Howatt, A. P. R. (1984). History of English language teaching. Oxford: Oxford University Press.

Kumaravadivelu, B. (2006). Understanding language teaching from method to post-method. London: Lawrence Erlbaum Associates, Publishers.

Larsen-Freeman, D. (1986). Techniques and principles in language teaching. Oxford: Oxford University Press.

Mackey, W. F. (1950). The meaning of method. English Language Teaching, 5, 4-10.

Mackey, W. F. (1965). Language teaching analysis. London: Longman. http://dx.doi.org/10.1093/elt/V.1.3

Mahmoodzadeh, M. (2011). The quest for resolving second language teaching dilemma: A review of the proposes solution using the last two decades. Academy Publisher, 1(10), 1375-1382. http://dx.doi.org/0.4304/tpls.1.10 
Mirhassani, A. (2006). Theories, approaches and methods in teaching English as a foreign language. Tehran: Zabankadeh.

Nunan, D. (1991). Language teaching methodology. London: Prentice-Hall.

Palmer, H. E. (1921). The principles of language study. London: Harrap.

Prabhu, N. S. (1990). There is no best method-why? TESOL Quarterly, 24, 161-176. http://dx.doi.org/10.2307/353586897

Richards, J. C. (1984). The secret life of methods. TESOL Quarterly, 18 (1), 7-23.

Richards, J. C. (1990). The language teaching matrix. Cambridge: Cambridge University Press.

Richards, J., \& Rodgers, T. (1982). Method: Approach, design, procedure. TESOL Quarterly, 16, 153-168.

Robinson, P. (1980). ESP (English for Specific Purposes). Oxford: Pergamon.

Salami-Nodoushan, M. A. (2006). Language teaching: state of the art. The Asian EFL Journal Quarterly, 8(1), 169-193.

Stern, H. H. (1983). Fundamental concepts of language teaching. Oxford: Oxford University Press.

Van Ek, J., \& Alexander, L. G. (1980). Threshold level English. Oxford: Pergamon.

Widdowson, H. G. (1990). Aspects of language teaching. Oxford: Oxford University Press.

Wilkins, D. A. (1976). Notional Syllabuses: A taxonomy of its relevance to foreign language curriculum development. Oxford: Oxford University Press. 